\title{
Longitudinal course of extrinsic allergic alveolitis in pigeon breeders
}

\author{
S J BOURKE, S W BANHAM, R CARTER, P LYNCH, G BOYD \\ From the Department of Respiratory Medicine, Royal Infirmary, Glasgow
}

\begin{abstract}
The purpose of this study was to assess the longitudinal course of pigeon breeders' disease by evaluating 24 patients with the acute form of the disease 10 years after their original diagnosis. Twenty one patients attended for clinical assessment, pulmonary function studies, chest radiography, and antibody measurement. Eighteen had continued to keep pigeons, emphasising their commitment to the hobby. Despite continued antigen exposure pigeon related symptoms had improved in most patients and only five still had troublesome symptoms. Four patients had residual abnormalities of pulmonary function or chest radiographs and three had chronic bronchitis. Fanciers had attempted to regulate their exposure to the birds by use of masks and by spending less time in their lofts but this is an unlikely explanation for the benign course of their disease, as levels of antibody to pigeon gammaglobulin remained high, suggesting that appreciable antigen exposure was still occurring. In most cases a state of equilibrium between host and antigen appeared to have developed. This observation has implications for the clinical management and understanding of the nature of the disease.
\end{abstract}

\section{Introduction}

Extrinsic allergic alveolitis is a condition in which various inhaled antigens provoke a hypersensitivity reaction in the lungs of sensitised individuals. ${ }^{1}$ The interaction of the antigen and the host response in producing extrinsic allergic alveolitis is complex and studies in animal models have shown that continued antigen challenge generally results in a waning of the pulmonary inflammatory response rather than progression of the disease..$^{2-5}$ Similarly, though farmer's lung may result in severe pulmonary fibrosis, ${ }^{67}$ the long term outcome after acute episodes may not be influenced by continued antigen exposure. ${ }^{89}$

Patients diagnosed as having pigeon breeders' disease, the extrinsic allergic alveolitis resulting from inhalation of antigens derived from pigeons, are usually advised to discontinue their hobby. Many, however, reject this medical advice and avoid doctors thereafter, so that the longitudinal course of this disease is poorly documented. Patients with pigeon breeders' disease often appear to have remained in a

Address for reprint requests: Dr Stephen Bourke, Department of Respiratory Medicine, Royal Infirmary, Glasgow G31 2ES.

Accepted 6 February 1989 state of equilibrium with the antigen for many years before the onset of symptoms ${ }^{1011}$ and, with the acute form of pigeon breeders' disease, may have normal pulmonary function despite having symptoms for up to 20 years. ${ }^{10}$ Dinda et al ${ }^{12}$ showed that pulmonary function improved in patients with pigeon breeders' disease who stopped being exposed but might deteriorate if exposure continued, and recently Schmidt et al ${ }^{13}$ reported an accelerated decline in serial lung function tests in five fanciers with symptoms who continued their hobby.

To assess further the longitudinal course of pigeon breeders' disease we undertook a follow up study of a cohort of 24 patients diagnosed 10 years previously.

\section{Patients and methods}

The population consisted of all the 24 patients we had identified during 1977 in a previous study as having the acute form of pigeon breeders' disease. ${ }^{14}$ The diagnostic criteria required at least one typical delayed (6-12 hours after exposure) respiratory symptom (dyspnoea, cough, or chest tightness) and one systemic symptom (fever, sweating, or arthralgia) occurring on at least three occasions with serological evidence of sensitisation to pigeon gammaglobulin."

Patients were invited to attend for detailed re- 
evaluation in 1987,10 years after the original diagnosis had been made. The circumstances of their exposure to pigeons were assessed by documenting the number of pigeons kept, the average number of hours spent in the loft in a week, the duration of exposure in years, and the use of protective masks. Details of age, sex, previous medical illness, smoking, and occupational history were noted. The present level of their delayed symptoms of pigeon breeders' disease was documented and symptoms of chronic bronchitis were sought by means of questions from the Medical Research Council's questionnaire. ${ }^{15}$

A venous blood sample was taken and sensitisation was quantified by measuring IgG antibody to pigeon gammaglobulin by means of an enzyme linked immunosorbent assay. ${ }^{1617}$ A posteroanterior chest radiograph was obtained and pulmonary function measured-forced vital capacity (FVC) and forced expiratory volume in one second $\left(\mathrm{FEV}_{1}\right)$ by spirometry, total lung capacity (TLC) and residual volume (RV) by helium dilution, and carbon monoxide diffusing capacity (transfer factor: TLCo) by the single breath method. Results were expressed as percentages of the predicted values and measurements greater than $80 \%$ of predicted were considered normal.

Statistical analysis was performed by means of $\chi^{2}$ and Student's $t$ tests.

\section{Results}

The 24 patients had a mean age at the time of diagnosis of 40 (range 20-58) years and one was female. No one was a current smoker but eight were ex-smokers. Three were unwilling to attend for study because they were no longer exposed to pigeons and were now symptom free: two had lost interest in the hobby and one had discontinued pigeon fancying because of his original symptoms. Twenty one attended for full reassessment: 18 of these had continued regular contact with pigeons and three were no longer exposed (two because of symptoms). Indices of the intensity of their exposure to the birds are shown in table 1 . Though the number of pigeons kept had increased over the 10 years $(p=0.012)$, fanciers now spent less

Table 1 Indices of avian exposure (mean (SEM) values)

\begin{tabular}{llll}
\hline & 1977 & 1987 & $p$ value \\
\hline Number of pigeons & $63(8 \cdot 9)$ & $82(12 \cdot 7)$ & $0.012^{*}$ \\
Weekly exposure (hours) & $30 \cdot 3(3 \cdot 2)$ & $20(2 \cdot 1)$ & $0 \cdot 001^{*}$ \\
Duration of exposure (years) & $\overline{30}(3 \cdot 8)$ & $29(3 \cdot 28)$ & - \\
IgG antibody (mg/l) & $43.5(6 \cdot 9)$ & $\mathrm{NS}$ \\
$\%$ using masks & 72 & $\mathrm{NS} \dagger$ \\
\hline
\end{tabular}

*Student's $t$ test.

$+\chi^{2}$ test. time in the loft $(p=0.001)$ and had regulated their exposure by increasing the use of masks and improving loft ventilation and husbandry methods. The three fanciers who had discontinued their hobby now had undetectable IgG antibody to pigeon gammaglobulin (figure), but a high level of antibody persisted in those with continued exposure to pigeons.

The typical delayed symptoms of pigeon breeders' disease had diminished in severity over the follow up period and only five patients still had troublesome symptoms related to exposure to the birds (table 2). Three patients fulfilled the criteria for chronic bronchitis despite being lifetime non-smokers and having no occupational exposure to dusts; one of these had airways obstruction with an $\mathrm{FEV}_{1} / \mathrm{FVC}$ ratio of $69 \%$ predicted normal. No other patient in the study had airways obstruction. None had developed appreciable respiratory disability or exertional dyspnoea. Three (patients 19-21) had air trapping, manifest by an increased RV/TLC ratio associated with restriction of lung volumes or impairment of gas diffusion (table 2). Three had abnormal chest radiographs, which showed a generalised reticulonodular pattern (patient 18) or basal (patient 19) or apical fibrosis (patient 20).

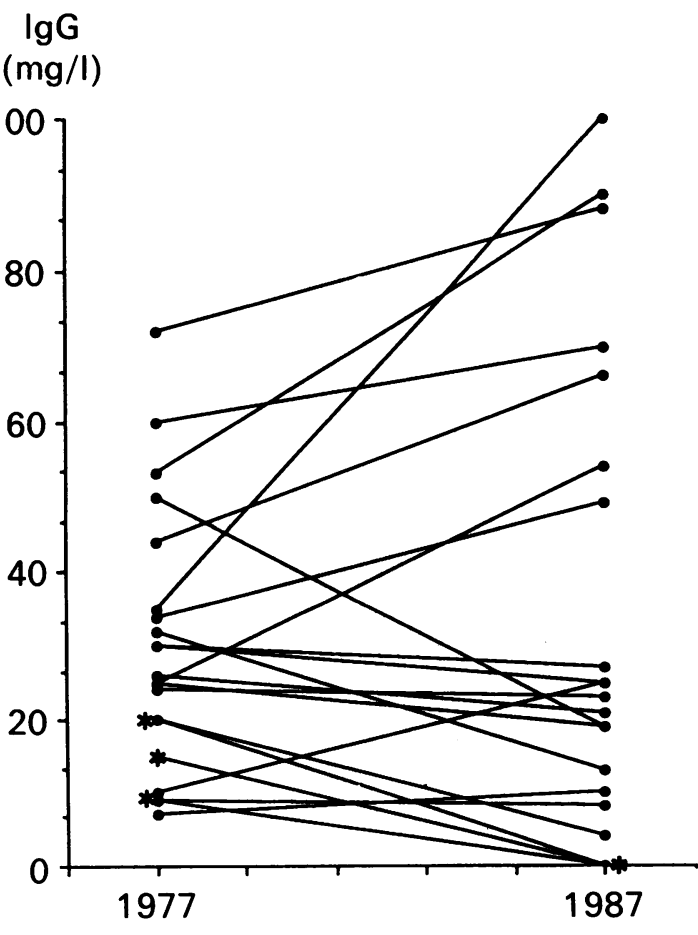

Concentrations of $\mathrm{IgG}$ antibody to pigeon gammaglobulin in 21 patients at the initial assessment and at follow up. * Stopped exposure to pigeons. 
Table 2 Results at follow up

\begin{tabular}{|c|c|c|c|c|c|}
\hline \multirow{2}{*}{$\begin{array}{l}\text { Patient } \\
\text { No }\end{array}$} & $T L C$ & $T L C O$ & \multirow{2}{*}{$\begin{array}{l}\text { Chest } \\
\text { radiograph }\end{array}$} & \multirow{2}{*}{$\begin{array}{l}\text { Delayed } \\
\text { PBD } \\
\text { symptoms* }\end{array}$} & \multirow{2}{*}{$\begin{array}{l}\text { Chronic } \\
\text { bronchitis* }\end{array}$} \\
\hline & \multicolumn{2}{|c|}{ (\% predicted) } & & & \\
\hline $\begin{array}{l}1-12 \\
13 \\
14 \\
15 \\
16 \\
17 \\
18 \\
19 \\
20 \\
21\end{array}$ & $\begin{array}{l}\mathrm{N} \\
89 \\
85 \\
82 \\
82 \\
95 \\
97 \\
91 \\
69 \\
75\end{array}$ & $\begin{array}{r}\mathbf{N} \\
81 \\
90 \\
96 \\
93 \\
117 \\
112 \\
72 \\
56 \\
83\end{array}$ & $\begin{array}{l}\mathbf{N} \\
\mathbf{N} \\
\mathbf{N} \\
\mathbf{N} \\
\mathbf{N} \\
\mathbf{N} \\
\text { Abn } \\
\text { Abn } \\
\text { Abn } \\
\mathbf{N}\end{array}$ & $\begin{array}{l}\text { Improved } \\
++ \\
++ \\
++ \\
++ \\
\text { Improved } \\
\text { Improved } \\
++ \\
\text { Improved } \\
\text { Improved }\end{array}$ & $\begin{array}{l}0 \\
+ \\
0 \\
+ \\
0 \\
+ \\
0 \\
0 \\
0 \\
0\end{array}$ \\
\hline
\end{tabular}

TLC-total lung capacity; TLco-transfer factor for carbon monoxide; PBD - pigeon breeders' disease; N-normal; Abnabnormal.

* + indicates symptom present, 0 absent, ++ troublesome.

\section{Discussion}

In this study most subjects had continued to keep pigeons, but the symptoms related to avian exposure had improved rather than progressed over the 10 years since they presented with acute pigeon breeders' disease and only four showed residual abnormalities on pulmonary function testing or chest radiography. None smoked at the time of diagnosis, which supports previous reports of an inverse relation between smoking and extrinsic allergic alveolitis. ${ }^{1819}$ All remained non-smokers, yet three developed chronic bronchitis and one showed evidence of large airways obstruction, indicating that pigeon breeders' disease may affect the bronchi in addition to the pulmonary interstitium. ${ }^{1920}$ No patient had developed appreciable respiratory disability. Fanciers had attempted to regulate their exposure to pigeons by measures such as the use of masks, but this is unlikely to explain the benign course of their disease as the persistence of high levels of antibody to pigeon gammaglobulin suggests that considerable antigen exposure was still occurring.

Extrinsic allergic alveolitis is not a uniform disease but rather a complex syndrome with a varying intensity of response to different provoking antigens and differences in clinical presentation and subsequent course. The particulate nature of the antigen in farmer's lung evokes a vigorous foreign body reaction with fibrosis and destructive histological changes, whereas the soluble avian antigens induce a less intense response. ${ }^{1}$ Direct comparisons between the prognosis of farmer's lung and of pigeon breeders' disease may therefore be inappropriate. Different clinical categories of extrinsic allergic alveolitis have been described. Fink et al ${ }^{10}$ devised a classification based on "acute," "subacute," and "chronic" forms of the disease, whereas Boyd et al ${ }^{21}$ emphasised the dynamic nature of the different symptom complexes and described patterns of "acute progressive," "acute intermittent non-progressive," and "recurrent nonacute" disease. The form and course of the disease may be determined by factors such as the intensity and frequency of antigen exposure, the severity of the first attack, and host factors governing immunological responses. Low grade, protracted antigenic stimulation such as occurs in relation to domestic budgerigars leads to an insidious disease, but intermittent intense exposure such as occurs in pigeon fanciers gives discrete clinical episodes. Subacute or chronic forms of the disease, which are characterised by the insidious onset of dyspnoea without typical acute symptoms, appear more likely to result in irreversible pulmonary damage. ${ }^{1021}$

There is a dichotomy in published reports between "good" and "poor" outcome with regard to the extrinsic allergic alveolitis of both farmer's lung ${ }^{6-9}$ and pigeon breeders' disease. ${ }^{10-13}$ The clinical picture is distorted by the self regulatory effect of symptoms, in that the patients with worse symptoms are likely to modify their antigen exposure and those with "acute progressive" disease will usually need to stop their exposure completely. Nevertheless, extrinsic allergic alveolitis undoubtedly regresses in some people despite continued antigenic stimulation. This is an intriguing phenomenon that remains difficult to explain adequately but has been confirmed in several animal models of the disease, where repeated antigen challenge has resulted in a waning rather than a progression of the pulmonary inflammatory response. $^{2-5}$ These animal models suggest that true immunological tolerance is not the explanation and this is supported by the persisting high antibody levels found in this study. Altered handling of the antigen may be an important factor. Braley et $a^{22-24}$ showed that the amount of antigen absorbed across the alveolar capillary barrier was reduced in sensitised animals, though permeability to other proteins was increased and higher levels of metabolites were found, suggesting increased pulmonary metabolism of the antigen.

This study has shown a favourable long term prognosis for patients with the acute form of pigeon breeders' disease. The predominant pattern was of "acute recurring non-progressive"18 disease, in which a state of equilibrium between host and antigen was achieved, with no deterioration in clinical condition over many years despite continued exposure to antigen and a persistent antibody response. Whereas doctors appreciate that it is often difficult for farmers to discontinue antigen exposure as their livelihood is at stake, they are often unsympathetic towards pigeon fanciers who wish to continue their hobby and, as a result, fanciers are generally reluctant to seek medical advice. Complete cessation of antigen exposure remains the safest advice for patients with pigeon 
breeders' disease, but it may not be necessary in all cases. Regulation of exposure by use of masks and changes in methods of animal husbandry may be helpful in reducing symptoms, but careful supervision of the evolution of the clinical, physiological, and immunological changes will be required to detect those fanciers who can safely continue their hobby.

\section{References}

1 Boyd G. Clinical and immunological studies in pulmonary extrinsic allergic alveolitis. Scott Med J 1978; 23:267-76.

2 Schuyler MR, Kleinerman J, Pensky JR, Brandt C, Schmitt D. Pulmonary response to repeated exposure to micropolyspora faeni. Am Rev Respir Dis 1983;128:1071-6.

3 Richerson HB, Richards DW, Swanson PA, Butler JB, Suelzer MJ. Antigen-specific desensitization in a rabbit model of acute hypersensitivity pneumonitis. J Allergy Clin Immunol 1981;68:226-34.

4 Richerson HB, Seidenfeld JJ, Ratajczak HV, Richards DW. Chronic experimental pneumonitis in the rabbit. Am Rev Respir Dis 1978;117:5-13.

5 Schuyler MR, Schmitt D. Experimental hypersensitivity pneumonitis: lack of tolerance. Am Rev Respir Dis 1984;130:772-7.

6 Barbee RA, Callies Q, Dickie HA, Rankin J. The longterm prognosis in farmer's lung. Am Rev Respir Dis 1968;97:223-31.

7 Braun SR, doPico GA, Tsiatis A, Horvath E, Dickie HA, Rankin J. Farmer's Lung Disease: Longterm clinical and physiologic outcome. Am Rev Respir Dis 1979;119:185-91.

8 Cormier Y, Belanger J. Longterm physiologic outcome after acute farmer's lung. Chest 1985;87:796-800.

9 Mönkare S, Haahtela T. Farmer's lung-a 5 year follow up of eighty six patients. Clin Allergy 1987;17:143-51.

10 Fink JN, Sosman AJ, Barboriak JJ, Schlueter DP, Holmes RA. Pigeon breeders' disease: a clinical study of a hypersensitivity pneumonitis. Ann Intern Med 1968;68:1205-19.

11 Banham SW, McSharry C, Lynch PP, Boyd G. Relationship between avian exposure, humoral immune res- ponse, and pigeon breeders' disease among Scottish pigeon fanciers. Thorax 1986;41:274-8.

12 Dinda P, Chatterjee SS, Riding WD. Pulmonary function studies in bird breeders' lung. Thorax 1969;24:374-8.

13 Du Wayne Schmidt C, Jensen RL, Christensen LT, Crapo RO, Davis JT. Longitudinal pulmonary function changes in pigeon breeders. Chest 1988;93:359-63.

14 Banham SW. Pigeon Breeders' disease-the clinical spectrum and humoral response. MD thesis, University of Edinburgh, 1987.

15 Report to the Medical Research Council. Definition and classification of chronic bronchitis for clinical and epidemiological purposes. Lancet 1965;i:775-9.

16 Anderson $\mathrm{P}$, Christensen $\mathrm{KM}$, Jensen $\mathrm{BE}$, et al. Antibodies to pigeon antigens in pigeon breeders. Detection of antibodies by an enzyme-linked immunosorbent assay. Eur $J$ Respir Dis 1982;63: 113-21.

17 McSharry CP, Banham SW, Lynch PP, Boyd G. Antibody measurement in extrinsic allergic alveolitis. Eur J Respir Dis 1984;65:259-65.

18 Warren CPW. Extrinsic allergic alveolitis: a disease commoner in non-smokers. Thorax 1977;32:567-9.

19 Anderson K, Morrison SM, Bourke S, Boyd G. Effect of cigarette smoking on the specific antibody response in pigeon fanciers. Thorax 1988;43:798-800.

20 Bourke S, Anderson K, Lynch P, et al. Chronic simple bronchitis in pigeon fanciers: the relationship of cough with expectoration to avian exposure and pigeon breeders' disease. Chest 1989;95:598-601.

21 Boyd G, McSharry CP, Banham SW, Lynch PP. A current view of pigeon fanciers' lung: a model for pulmonary extrinsic allergic alveolitis. Clin Allergy 1982;12(suppl):53-9.

22 Braley JF, Dawson CA, Moore VL. Immunologic block against antigen absorption from isolated perfused rabbit lungs. J Immunol 1978;121:926-9.

23 Braley JF, Peterson LB, Dawson CA, Moore VL. Effect of hypersensitivity on protein uptake across the airblood barrier of isolated rabbit lungs. $J$ Clin Invest 1979;63:1103-9.

24 Braley JF, Dawson CA, Moore VL, Cozzini BO. Absorption of inhaled antigen into the circulation of isolated lungs from normal and immunized rabbits. $J$ Clin Invest 1978;61:1240-6. 